\title{
The Effect of High Body Mass Index on Self-Esteem and Sexual Functions in Obese Females Admitted to The Plastic Reconstructive and Aesthetic Surgery Department
}

\author{
Anvar Ahmedov ${ }^{1}$, Yesim Ahmedov ${ }^{2}$ \\ ${ }^{1}$ Istanbul Basaksehir Cam ve Sakura City Hospital, Clinic of Plastic, Reconstructive and Aesthetic Surgery, Istanbul, Turkey. \\ ${ }^{2}$ Istanbul Okan University, Health Sciences Institute, Public Health Nursing, Istanbul, Turkey. \\ Correspondence Author: Anvar Ahmedov \\ E-mail: anvar.ahmedov@yahoo.com \\ Received: $05.06 .2020 \quad$ Accepted: 15.09 .2021
}

\begin{abstract}
Objective: Obesity can be defined as body weight above the desired level. Obesity has gone beyond being a cosmetic problem and is now referred to as a disease, and there is a currently significantly increasing number of studies examining the relationship between the obesity and psychopathology. The psychological and social effects of obesity also affect the self-confidence of the individual and the behavioral orientation at the onset of sexual intercourse and avoidance. The aim of this study was to determine whether high body mass index has an effect on selfesteem and sexual functions in obese women who were referred to an obesity center.
\end{abstract}

Methods: This descriptive study was conducted between 1.11.2018 and 15.01.2020. A total of 202 patients referred from the plastic surgery department to the obesity centre were included in the study. All the patients were assessed twice within a 7-month period with the Rosenberg Self-Esteem Scale, Body Perception Scale and Arizona Sexual Experiences Scale.

Results: Of the 202 women evaluated, $66.3 \%$ were in the 51-70 years age range, and 52\% had a body mass index in the range of $35-39.9$. Evaluation of the two applications of the scales showed a significant positive relationship between the first scale and the second scale scores seven months after weight loss.

Conclusion: The results of this study showed that a decrease in body weight had a positive effect on body perception and on sexual satisfaction.

Keywords: Obesity, sexual satisfaction, self esteem, body perception

\section{INTRODUCTION}

Nutrition is one of the most important current health problems, because inadequate or unbalanced nutrition can have anegative effect on health. Obesity is generally classified using body mass index (BMI), which is calculated as body weight in kilograms divided by height in meters squared $(\mathrm{kg} /$ m2) (1). Obesity can also be defined as body weight above the desired level (2).

Being overweight is defined as a BMI value between 25 and 30 according to the Centers for Disease Control and Prevention of the USA (3).

The human body is mainly composed of active mass (muscle, liver, heart, etc.), adipose tissue (fat), extracellular fluid (blood, lymph, etc.), and connective tissue (skin, bone connective tissue) As a structure, obesity is characterized by relative increment in fat mass compared to other body components (2). Intra-abdominal fat mass in particular is responsible for the obesity condition and could lead to a higher risk of insulin resistance and heart disease (4).
Environmental, neurological, physiological, biochemical, cultural and psychological factors in addition to heredity, are effective in relation to each other and make the prevention and treatment of obesity more difficult and complicated (5).

With increasing incidence in recent years, obesity has gone beyond being a cosmetic problem and is now referred to as a disease. Recently, there has been a significant increase in the number of studies examining the relationship between obesity and psychopathology. These studies have suggested that obesity is a complex condition which could lead to anxiety, depression, and consequently deterioration in personal health and quality of life $(6,7)$. In some other studies of body perception in obese individuals, it has been reported that BMI has a significant effect on body dissatisfaction (8) and an obese group had more body dissatisfaction than a nonobese group (9). In addition, increased sexual dysfunction and higher comorbidity rates have been mentioned $(6,7)$. The mechanism of sexual dysfunction secondary to obesity is multifactorial (10). The psychological and social effects of 
obesity also affect the self-confidence of the individual and behavioral orientation at the onset of sexual intercourse and avoidance. The place of sexuality in human life is indisputable and can be said to have significant effects on quality of life for both men and women.

However, few studies have examined the effect of obesity on sexual functions in women. The characteristics, physiology and mechanisms of female sexual dysfunction differ from and are more complex than those of men. Female sexual dysfunction has an impact on quality of life and a decrease in quality of life will cause sexual dysfunction (11). The aim of the current study was to determine whether high body mass index has an effect on self-esteem and sexual functions in obese women who were referred to an obesity center.

\section{METHODS}

This descriptive study was conducted on 202 patients in the Obesity Center of our hospital between 1.11.2018 and 15.01.2020. The Ethics Committee of Istanbul Okan University approved the study with a number 14 decision by 22.01.2020 date. All the study procedures were applied in accordance with the 2008 Helsinki Declaration.

The study inclusion criteria were as follows:

1 - BMI of $\geq 30$,

2 - Voluntary participation,

3-Female gender, aged 18-70 years,

4 - Education level of at least primary school,

$5-$ In an established sexual relationship.

Obese female patients who presented at the Plastic, Reconstructive and Aesthetic Surgery service for body shaping were referred to the Obesity Center to obtain a permanent and appropriate weight range and to prepare for surgery. The obese patients were informed that they were overweight and surgery could result in more complications if performed before reaching a permanent and appropriate weight, and there could be poorer outcomes with long-term weight loss.

Height and weight were measured and body mass index values were calculated according to the index formula suggested by the World Health Organization in 1988 (12). Each subject was interviewed individually for 20 mins under suitable conditions. The evaluation scale questionnaires were completed on first admission to the Obesity Center and after seven months when the study was ended.

\subsection{Patient Information and Demographic Data Form}

This form included the following data: Age, BMI, education level, occupation, marital status, education of the spouse, occupation, number of children, economic status, smoking, alcohol, drug use, exercise, diet, and eating behavior. The form related to obesity questioned emotional state, family structure, parents, and siblings, age at onset of obesity, the presence of any triggering factor, psychiatric admission due to obesity, use of drugs to prevent obesity, opinions about obesity, and the effects of obesity on social life.

\subsection{Rosenberg Self-Esteem Scale}

This scale was developed by Morris Rosenberg in 1963, and has been used as a measurement tool in many studies following reliability and validity trials conducted in the USA. In Turkey, the validity and reliability coefficients were calculated as 71 and 75, respectively, by Çuhadaroğlu. The Rosenberg Self-Esteem Scale is a self-report scale consisting of 63 multiple-choice questions. The first ten items of the scale were utilized to measure the self-esteem status in this study. Items 1, 2, 4, 6, and 7 question positive self-assessment, and items $3,5,8,9$, and 10 question negative self-assessment, with scores ranging from 0 to 3 . Items $2,5,6,8$, and 9 are reverse scored. The total score range is between $0-30$, with $15-25$ points indicating that self-esteem is sufficient, and $<15$ points indicating low self-esteem (13).

\subsection{The Body Perception Scale}

This scale was developed in 1953 by Secord and Jourand, and the validity and reliability of the scale were measured in 1989 by Hovardaoğlu. The scale consists of 40 items and each item is related to an organ or part of the body (such as arms, legs, face) or a function (such as the level of sexual activity). Each item is scored from 1 to 5 , providing a total score between 40 and 200. A higher score indicates a higher level of satisfaction. The cut-off score of the scale was 135 and those with a score $<135$ were defined as low body perception (14).

\subsection{Arizona Sexual Experiences Scale (ASEX)}

This is a Likert-type self-assessment scale consisting of five questions, which meet the current diagnostic criteria of DSM-IV and ICD-10 developed for sexual dysfunction characterization. Validity and reliability studies of the scale for a Turkish population have been conducted. The total scale score varies from 5 to 30 with each item scored from 1 to 6. Sexual dysfunction is considered to be present in patients with a total scale score of $\leq 19$, or with any sub-dimension score of $\geq 5$, or with 3 or more sub-dimension scores of 4 . Low scores indicate that sexual response is strong, easy and satisfactory, while higher scores indicate the presence of a possible sexual dysfunction (15).

\subsection{Statistical Analysis}

Data obtained in the study were analyzed statistically using IBM SPSS Statistics vn. 21 software (SPSS IBM, Chicago, IL, USA). Conformity of the data to normal distribution was evaluated with the Kolmogorov-Smirnov test, and the homogeneity was tested. Descriptive statistical methods (mean, standard deviation, frequency), t tests and correlation 
analysis were used to evaluate the study data. A value of $p<0.05$ was accepted as statistically significant.

\section{RESULTS}

Of the total 202 women evaluated, $66.3 \%$ were in the $51-70$ age range, $52 \%$ had $\mathrm{BMI}$ in the range of $35-39.9$, and $51.5 \%$ had a waist-hip ratio of $\geq 0.85$. Education level of primary school or lower was reported by $43.1 \%$ of the women, $68.3 \%$ were housewives, $66.8 \%$ were married, $55 \%$ had three or more children, $37.1 \%$ were aged $<20$ years at the onset of obesity and $83.7 \%$ consumed excessive carbohydrate and fatty food content. When the reason for the onset of obesity was examined, it was found that $63.4 \%$ gained weight after stopping smoking and $71.8 \%$ when going through the menopause. The income level of $44.6 \%$ was low, $47 \%$ were taking medication for obesity, $55.9 \%$ had presented at the Psychiatry Dept because of obesity, and $80.2 \%$ stated that they ate more food when they were sad (Table 1).

Table 1. Sociodemographic characteristics of Obese Women Applying to an Obesity Center

\begin{tabular}{|c|c|c|}
\hline & n & $\%$ \\
\hline \multicolumn{3}{|l|}{ Age } \\
\hline $18-30$ & 17 & 8.4 \\
\hline $31-50$ & 51 & 25.2 \\
\hline $51-70$ & 134 & 66.3 \\
\hline \multicolumn{3}{|l|}{ BMI } \\
\hline $30-34,9$ & 26 & 12.9 \\
\hline $35-39,9$ & 105 & 52.0 \\
\hline$\geq 40$ & 71 & 35.1 \\
\hline \multicolumn{3}{|l|}{ Waist Hip Ratio } \\
\hline ? 0,8 & 6 & 3.0 \\
\hline $0,8-0,85$ & 92 & 45.5 \\
\hline$\geq 0,85$ & 104 & 51.5 \\
\hline \multicolumn{3}{|l|}{ Education Level } \\
\hline Primary school or lower & 87 & 43.1 \\
\hline High School or lower & 92 & 45.5 \\
\hline Undergraduate or graduate & 23 & 11.4 \\
\hline \multicolumn{3}{|l|}{ Job } \\
\hline Housewife & 138 & 68.3 \\
\hline Civil Servant Or Laborer & 9 & 4.5 \\
\hline Tradesman & 36 & 17.8 \\
\hline Retired & 19 & 9.4 \\
\hline \multicolumn{3}{|l|}{ Marital Status } \\
\hline Single & 57 & 28.2 \\
\hline Married & 135 & 66.8 \\
\hline Widow & 10 & 5.0 \\
\hline \multicolumn{3}{|l|}{ Child } \\
\hline None & 11 & 5.4 \\
\hline $1-3$ & 80 & 39.6 \\
\hline$>3$ & 111 & 55.0 \\
\hline \multicolumn{3}{|l|}{ Economic Level } \\
\hline Income<Expenditure & 90 & 44.6 \\
\hline Income $=$ Expenditure & 32 & 15.8 \\
\hline
\end{tabular}

\begin{tabular}{|c|c|c|}
\hline Income $>$ Expenditure & 80 & 39.6 \\
\hline \multicolumn{3}{|l|}{ Beginning Age Of Obesity } \\
\hline Under 20 & 75 & 37.1 \\
\hline $20-30$ & 71 & 35.1 \\
\hline 30 or more & 56 & 27.7 \\
\hline \multicolumn{3}{|l|}{$\begin{array}{l}\text { Consumed excessive carbohydrate } \\
\text { and fatty food content }\end{array}$} \\
\hline Exists & 169 & 83.7 \\
\hline None & 33 & 16.3 \\
\hline \multicolumn{3}{|l|}{ Gained weight after stopping smoking } \\
\hline Exists & 128 & 63.4 \\
\hline None & 74 & 36.6 \\
\hline \multicolumn{3}{|l|}{$\begin{array}{l}\text { Gained weight when going through } \\
\text { the menopause }\end{array}$} \\
\hline Exists & 145 & 71.8 \\
\hline None & 57 & 28.2 \\
\hline $\begin{array}{l}\text { Presented at the Psychiatry Dept } \\
\text { because of obesity }\end{array}$ & & \\
\hline Exists & 113 & 55.9 \\
\hline None & 89 & 44.1 \\
\hline \multicolumn{3}{|l|}{ Medication For Obesity } \\
\hline Exists & 95 & 47.0 \\
\hline None & 107 & 53.0 \\
\hline \multicolumn{3}{|l|}{ Eat When You Are Happy } \\
\hline Exists & 109 & 54.0 \\
\hline None & 93 & 46.0 \\
\hline \multicolumn{3}{|l|}{ Eat When You Are Sad } \\
\hline Exists & 162 & 80.2 \\
\hline None & 40 & 19.8 \\
\hline \multicolumn{3}{|l|}{ Affecting social life due to obesity } \\
\hline I Don't Want To Join Social Life & 141 & 69.8 \\
\hline I Never Join Social Life & 61 & 30.2 \\
\hline \multicolumn{3}{|l|}{ Are Mother And Father Together } \\
\hline Together & 68 & 33.7 \\
\hline Divorced & 78 & 38.6 \\
\hline Parents Dead & 56 & 27.7 \\
\hline \multicolumn{3}{|l|}{ Is Mother Obese? } \\
\hline Yes & 185 & 91.6 \\
\hline No & 17 & 8.4 \\
\hline \multicolumn{3}{|l|}{ Is Father Obese? } \\
\hline Yes & 106 & 52.5 \\
\hline No & 96 & 47.5 \\
\hline \multicolumn{3}{|l|}{ Is Sister Obese? } \\
\hline Yes & 175 & 86.6 \\
\hline No & 27 & 13.4 \\
\hline
\end{tabular}

In evaluation of the data obtained from the second applications of the questionnaires, there was seen to be a significant positive relationship between the first Rosenberg Self-Esteem Scale score and the second scale score applied after seven months after weight loss. According to the results of the Paired Samples t-test, a decrease in BMI had a positive effect on self-esteem ( $p<0.001)$. According to the two applications of the Arizona Sexual Satisfaction Scale, a decrease in BMI had a positive effect on sexual satisfaction $(p<0.001)$. When these two body perception scales were 
compared, a decrease in BMI was determined to have a positive effect on body perception in obese women $(p<0.001)$. A statistically significant positive correlation was determined between BMI and eating when unhappy $(p<0.001)$ (Table 2). A statistically significant positive correlation was found between the BMI of women and admission to obesity-related psychiatry $(p<0.001)$ (Table 3$)$.

The analyses applied showed a statistically significant positive relationship between low income level of the obese women and the Rosenberg Self-Esteem Scale scores, and between low income and the Body Perception Scale scores $(p<0.001, p<0.001)$. No statistically significant relationship was determined between low income level and the Arizona Sexual Satisfaction Scale points.

Table 2. The Relationship Between the Sad Eating Behavior of Obese Women and High Body Mass Index (BMI)

\begin{tabular}{|l|c|c|c|}
\hline & $\mathbf{n}$ & $\mathbf{r}$ & $\mathbf{p}$ \\
\hline $\begin{array}{l}\text { Eating when unhappy } \\
\text { BMI }\end{array}$ & 202 & 0,551 & $<0,001$ \\
\hline
\end{tabular}

A statistically significant positive correlation was determined between $B M I$ and eating when unhappy $(p<0.001)$

Table 3. The Relationship Between Obesity-Related Psychiatry Clinic Apply Status and High Body Mass Index (BMI) of Obese Women

\begin{tabular}{lccc|}
\hline & $\mathbf{n}$ & $\mathbf{r}$ & $\mathbf{p}$ \\
$\begin{array}{l}\text { Obese which has psychiatry } \\
\text { clinic apply }\end{array}$ & 202 & 0,646 & $<0,001$ \\
BMI & & &
\end{tabular}

A statistically significant positive correlation was found between the BMI of women and admission to obesity-related psychiatry $(p<0.001)$.

\section{DISCUSSION}

In recent years, the prevalence of obesity has greatly increased in all regions of the world, in both rich western countries and poorer countries. There is a need for collaboration between people, governments, the media and the food industry to change the societal environment to be able to reduce weight gain, and encourage healthy lifestyles in all age groups, but especially in children and adolescents (16).

In the current study, the age at onset of obesity was $18 \pm$ 3.4 years, which supports the findings of Tuzun et al (17). However, there are conflicting data in literature about the age at onset of obesity. It has been reported that less than a third of obese patients were obese in childhood, and although it can start at any age, obesity is mostly reported to develop after puberty (18).

In the current study, the mean rate of obesity in parents and siblings of obese participants was significantly higher than in non-obese individuals. This suggests that having obese parents can increase the tendency to obesity during childhood. It has been mentioned in the literature that obesity in close relatives was considered a genetic risk factor for obstetric obesity (19).
The responses given by the obese women to the question of "What is the most important factor causing your obesity?" were "Eating too much carbohydrate and fatty foods" at the rate of $83.7 \%$, followed by entering menopause and quitting sports. Previous papers, have reported physical inactivity as the most important reason for the onset of obesity $(18,20$, 21). In a study by Bray, it was reported that physical inactivity contributed significantly to the onset of obesity at an approximate rate of $67.5 \%$ (18). Wilson et al. reported that obesity was most common in men with a sedentary lifestyle, while pregnancy was a major factor for women (22).

In the current study, "emotion-induced eating" (sad, cheerful, anxious, angry, etc) was significantly higher in obese group $(p<0.001)$, and it was observed that obese participants ate more when upset. Other similar studies have shown that emotional eating is related to weight gain (23). Canetti et al, reported that increased eating in conditions of distress, depression, and fatigue, resulted in a decrease in fear, tension and pain (24). Ganley et al. stated that emotional eating behavior was related to negative emotions such as anger, depression, distress, anxiety and loneliness (23).

In the current study, it was observed that the self-esteem of obese subjects was remarkably lower than that of nonobese subjects $(p=0.001)$. The vast majority of research papers have shown a linear relationship between obesity and decreased self-esteem $(25,26)$. In a previous study conducted to examine the levels of depression and selfesteem in obese women, $42.5 \%$ were depressed and $58.6 \%$ had low self-esteem (27). In a study by Ogden and Evans, it was found that depression was higher and self-esteem was lower in obese cases (28), and Kartal also reported lower self-esteem in obese participants (29). In a prospective study conducted with 64 women by Galletly et al., a decrease in depression rate and increase in self-esteem were recorded in correlation with weight loss (30). In the current study, after 7 months of losing weight, the evaluation scales were applied again and there was found to be a significant increase in the total scores of the self-esteem scale second application.

The current study obese group gave negative feedback that they were dissatisfied with their body at a statistically significantly higher rate than the non-obese group ( $p<$ 0.001). In a study by Caldwell et al., it was suggested that BMI had a significant effect on body dissatisfaction status (8). Sarwer et al. reported that obese individuals had a higher level of body dissatisfaction compared to a non-obese group (9). In another study conducted using the Body Dysmorphic Disorder Scale and Body Shape Questionnaire, it was found that more than $80 \%$ of female participants had negative body perception (31). Cash reported that obese people who reduced their weight by $24 \%$ using a very low-calorie diet experienced significant improvements in all aspects of body perception (32). In the current study, the weight loss of patients was found to contribute to a positive change in body perception according to the results of the the second body perception scale applied at the end of the $7^{\text {th }}$ month. 
It was also observed that obese patients had impairments in sexual functions, and sexual satisfaction was negatively affected compared to the non-obese group. The causes of the formation of sexual dysfunction accompanying obesity are multifactorial, and there are high comorbidity rates that will clearly cause sexual dysfunction especially in morbid obesity. The effect of some common diseases such as DM and HT (33), psychiatric problems such as depression and anxiety, and the drugs used for sexual functions are well-known (10). Several studies have focused on defining the characteristics of the sexual life of obese women with sexual dysfunction. The literature shows that sexual desire and orgasm disorders are common in women (34). In the current study, obese women had low sexual satisfaction. In a study by Kaneshiro et al. conducted with 6690 women in the USA, it was reported that an increase in obesity negatively affected female sexuality (35). Kolotkin et al. evaluated the quality of life and sexual satisfaction of subjects with mean BMI level over $40 \mathrm{~kg} / \mathrm{m}^{2}$, and found that more than half of the overweight women had low sexual satisfaction and avoided having sexual intercourse because of their low body perception (36). In the current study, there was observed to be an increase in the scores obtained from the sexual satisfaction dimension of the ASEX scale with the decrease in BMI in the second application of the scale after seven months. The sexual satisfaction level and desire were seen to increase in obese women as they lost weight.

When the income level was low in obese women, it was determined that BMI increased and self-esteem decreased. The fact that this study was conducted in a public hospital on subjects with a low socio-economic level could have affected this result. A low socioeconomic level and a greater number of people in the household can cause obesity by lowering the amount spent on sufficient and balanced nutrition. In another study that examined the frequency of obesity and the factors affecting obesity in married women living in slum areas, there was determined to be a significantly positive relationship between $\mathrm{BMI}$ and the number of people in the household. Similarly, Blumel et al reported that an increase in the number of people living in the home increased the risk of obesity 1.31-fold (37).

\section{CONCLUSION}

Obesity causes many health problems, both mental and physical. It can be seen that the general quality of life of obese individuals is diminished as a result of both health problems and social difficulties. Therefore, factors causing obesity and their consequences should be considered in multi-dimensional way. Investigation of biological, psychological and social factors that contribute to obesity can be a guide in preventing or reducing obesity. There is a need for collaboration of society, government, the media, and the food industry to change the environment to be able to reduce weight gain, and to promote healthy lifestyles in all age groups, especially in children and adolescents.
There is increasing interest in studies on the psychosocial aspects of obesity. Previously conducted research trials have shown that childhood and adolescent traumas are an important factor in the development of obesity as was also reported in this study. In addition, negative body perception and low self-esteem seen in obese individuals are regarded as an important condition that should be addressed in the treatment of obesity.

\section{REFERENCES}

[1] Engin, A. The definition and prevalence of obesity and metabolic syndrome. In Obesity and Lipotoxicity 2017; 1-17. Springer, Cham.

[2] Soykan A. The reliability and validity of Arizona sexual experiences scale in Turkish ESRD patients undergoing hemodialysis. Int J Impot Res 2004; 16:531-534. PMID: 15175639 .

[3] Centers for Disease Control and Prevention of the USA 2017. https://www.cdc.gov/obesity/adult/defining.html , access: 20.10.2019.

[4] Stefan N, Kantartzis K, Machann J, Schick F, Thamer C, Rittig K, Balletshofer B, Machicao F, Fritsche A, Häring HU. Identification and characterization of metabolically benign obesity in humans. Arch Intern Med. 2008 Aug 11;168(15):1609-16.

[5] Korugan U, Damci T, Ozbey N, Ozer E. (editors). Clinical Obesity. İstanbul: Obesity Working Group Publication; 2000. p. 33-44.

[6] Derby CA, Mohr BA, Goldstein I, Feldman HA, Johannes CB, Mckinlay JB. Modifiable risk factors and erectile dysfunction: can lifestyle changes modify risk? Urology 2000; 56:302-306.

[7] Adolfsson B, Elofsson S, Rössner S, Unden AL. Are sexual dissatisfaction and sexual abuse associated with obesity? A population-based study. Obes Res 2004; 12:1702-1709. PMID: 15536235.

[8] Caldwell MB, Brownell KD, Wilfley DE. Relationship of weight, body dissatisfaction and self esteem in African American and white female dieters. International Journal of Eating Disorders 1997; 22: 127-130.

[9] Sarwer DB, Wadden TA, Foster GD. Assesment of body image dissatisfaction of obese women: specificity, severity, and clinical significance. Journal of Consulting and Clinical Psychology 1998; 66: 651-654.

[10] Laumann EO, Paik A, Rosen RC. Sexual dysfunction in the United States: prevalence and predictors. JAMA 1999; 281:537 - 544.

[11] Kettaş E, Çayan F, Akbay E, Kiykim A, Cayan S. Sexual dysfunction and associated risk factors in women with endstage renal disease. J Sex Med 2008; 5:872-877 (In Turkish).

[12] Baysal A. Nutrition. Ankara: Hacettepe University Press; 1990. p. 61.

[13] Çuhadaroğlu F. Self-esteem in adolescents, Unpublished master thesis, Ankara, Hacettepe University, Department of Psychiatry. 1986 (In Turkish).

[14] Hovardaoğlu S. Reliability and validity study of body perception scale. In: Özdemir YD. Satisfaction levels of schizophrenic and major depressive patients from body images. Unpublished Master's Thesis, Ankara, Institute of Social Sciences. 1990 (In Turkish).

[15] McGahuey CA, Gelenberg AJ, Laukes CA, Moreno FA, Delgado $\mathrm{PL}, \mathrm{McKnight} \mathrm{KM}$, Manber R. The Arizona Sexual Experience 
Scale (ASEX): reliability and validity. J Sex Marital Ther 2000; 26:25-40.

[16] Prevention and management of the global epidemic of obesity. Report of the WHO Consultation on Obesity. Geneva 1997; WHO 2 https://www.who.int/nutrition/publications/obesity/ WHO_TRS_894/en/, access: 10.10. 2019.

[17] Tüzün M, Kabalak T, Yılmaz C. General features of obesitydefinition, frequency, diagnosis, classification, types, degrees and complications. In: Yilmaz C, editor. Obesity and Its Treatment, Istanbul: March Printing 1999. p. 11-28 (In Turkish).

[18] Bray GA. Classification and evolution of the obesities. Med Clin North Am 1989; 73: 161-184.

[19] WHO Technical Report Series-854: Physical Status: The Use and Interpretation of Antropometry. 1 Edition Geneva 1995; WHO. https://www.who.int/childgrowth/publications/ physical_status/en/, access: 10.10.2019.

[20] Taras HL, Sallis JF, Patterson TL, Nader PR, Nelson JA. Television's influence on children's diet and physical activity. J Dev Behav Pediatr. 1989; 10(4):176-80. PMID: 2768484.

[21] Buchowski MS, Sun M. Energy expenditure, television viewing and obesity. Int J Obes 1996; 20:236-244.

[22] Wilson DJ, Foster DW, Kronenberg MH, Larsen PR. Williams Textbook of Endocrinology 9th Edition. Philadelphia: WB. Saunders Company 1998. p. 1102-1120.

[23] Ganley RM. Emotion and eating in obesity: a review of the literature. Int J Eat Disord 1989; 8: 343-361. https:// doi.org/10.1002/1098-108X(198905)8:3<343::AIDEAT226.008.0310>3.0.CO;2-C

[24] Canetti L, Bachar E, Berry EM. Food and emotion. Behav Process 2002; 60:157-164

[25] Telch CF, Agras WS. Obesity, binge eating and psychopathology: Are they related? Int J Eat Disord 1994; 5: 53-61.

[26] French SA. Self-esteem and change in BMI over three years in a cohort of adolescencts. Obes Res 1996;427-433.
[27] Pınar R. Depression, self-esteem and body image in obese: a comparative study. CU Journal of Nursing School; 2002; 6 (1): 30-41 (In Turkish)

[28] Ogden J, Evans C. The problem with weighting: effects on mood, self-esteem and baody image. Int J Obes Relat Metab Disord; 1996:20(3):272-277.

[29] Kartal SMA. Obesity and its psychological correlates: Appearance-esteem, Selfesteem and Loneliness. Unpublished Master Dissertation, Ankara, Ankara University. 1996 (In Turkish).

[30] Galletly C, Clark A, Tomlinson L ve ark. A group program for obese, infertile women: weight loss and improved psychological health. J Psychosom Obstet Gynaecol, 1996;17: 125-128. https://doi.org/10.3109/016.748.29609025672.

[31] Rosen, JC, Orosan P, and Reiter J. Cognitive Behaviour Therapy for negative body image in obese women. Behaviour Therapy, 1995:26;25-42. PMID: 8819023.

[32] Cash TF. Body image and weight changes in a multisite comprehensive very low calorie diet program. Behavior Therapy, 1994;25:239-254.

[33] Esposito K, Ciotola M, Giugliano F, Bisogni C, Schisano B, Autorino R, Cobellis L, De Sio M, Colacurci N, Giugliano D. Association of body weight with sexual function in women. Int J Impot Res 2007; 19:353-357.

[34] Weaver AD, Byers ES. The relationships among body image, body mass index, exercise, and sexual functioning in heterosexual women. Psychol Women Q 2006; 30:333-339.

[35] Kettaş E, Çayan F, Akbay E, Kiykim A, Cayan S. Sexual dysfunction and associated risk factors in women with endstage renal disease. J Sex Med 2008; 5:872-877.

[36] Kolotkin RL, Crosby RD, Williams GR, Hartley GG, Nicol S. The relationship between health-related quality of life and weight loss. Obes Res 2001; 9:564-571. PMID: 11557837.

[37] Balcı-Yangın $\mathrm{H}$, Sevi H. Prevalence of obesity in married women living in slums and affecting factors. Van Med J 2016;23:1-6.

How to cite this article: Ahmedov A, Ahmedov Y. The Effect of High Body Mass Index on Self-Esteem and Sexual Functions in Obese Females Admitted to The Plastic Reconstructive and Aesthetic Surgery Department. Clin Exp Health Sci 2021; 11: 683-688. DOI: 10.33808/clinexphealthsci.748259 